SMALL INTESTINE

\title{
T cells in peripheral blood after gluten challenge in coeliac disease
}

\author{
R P Anderson, D A van Heel, J A Tye-Din, M Barnardo, M Salio, D P Jewell, A V S Hill
}

Gut 2005;54:1217-1223. doi: 10.1136/gut.2004.059998

See end of article for authors' affiliations

Correspondence to:

Dr R P Anderson,

Autoimmunity and Transplantation Division,

Walter and Eliza Hall

Institute, c/o Post Office

$\mathrm{RMH}$, Victoria, Australia

3050; banderson@

wehi.edu.au

Revised version received 23 February 2005

Accepted for publication

24 February 2005

\begin{abstract}
Background: Current understanding of $T$ cell epitopes in coeliac disease (CD) largely derives from intestinal T cell clones in vitro. T cell clones allow identification of gluten peptides that stimulate $T$ cells but do not quantify their contribution to the overall gluten specific T cell response in individuals with CD when exposed to gluten in vivo.

Aims: To determine the contribution of a putative dominant $T$ cell epitope to the overall gliadin $T$ cell response in HLA-DQ2 CD in vivo.

Patients: HLA-DQ2+ individuals with CD and healthy controls.

Methods: Subjects consumed $20 \mathrm{~g}$ of gluten daily for three days. Interferon $\gamma$ (IFN- $\gamma$ ) ELISPOT was performed using peripheral blood mononuclear cells (PBMC) to enumerate and characterise peptide and gliadin specific T cells before and after gluten challenge.

Results: In 50/59 CD subjects, irrespective of homo- or heterozygosity for HLA-DQ2, IFN- $\gamma$ ELISPOT responses for an optimal concentration of A-gliadin 57-73 Q-E65 were between 10 and 1500 per million PBMC, equivalent to a median $51 \%$ of the response for a "near optimal" concentration of deamidated gliadin. Whole deamidated gliadin and gliadin epitope specific T cells induced in peripheral blood expressed an intestinal homing integrin ( $\alpha 4 \beta 7$ ) and were HLA-DQ2 restricted. Peripheral blood T cells specific for A-gliadin 57-73 Q-E65 are rare in untreated CD but can be predictably induced two weeks after gluten exclusion.

Conclusion: In vivo gluten challenge is a simple safe method that allows relevant $\mathrm{T}$ cells to be analysed and quantified in peripheral blood by ELISPOT, and should permit comprehensive high throughput mapping of gluten $T$ cell epitopes in large numbers of individuals with CD.
\end{abstract}

G luten specific HLA DQ2 and DQ8 restricted CD4 T cells are central to the pathogenesis of coeliac disease (CD). Understanding the specificity (epitopes) of T cells and their consistency between individuals in vivo is critical for the development of alternatives to current diagnostics and dietary treatment.

To best reflect their in vivo specificity, frequency, and behaviour, freshly isolated primary $\mathrm{T}$ cells in culture for less than one day are ideal as longer term culture leads to the potential for proliferation of naïve $\mathrm{T}$ cells and alteration in $\mathrm{T}$ cell phenotype and function. ${ }^{1-3}$ Secretion of cytokines, such as those abundantly expressed in the inflamed small intestinal mucosa in CD (interferon $\gamma(\mathrm{IFN}-\gamma)$ and interleukin 4 $(\mathrm{IL}-4)),{ }^{4}$ is characteristic of effector and memory T cells. ${ }^{13}$ In contrast, naïve T cells secrete abundant IL-2 and only with successive days in culture do they acquire the ability to secrete IFN- $\gamma$ and IL-4. ${ }^{3}$ However, in almost all chronic immune mediated diseases, the frequencies of "relevant" antigen specific CD4 T cells in peripheral blood are close to or several orders of magnitude below the levels of detection for most short term assays, including cytokine ELISA, intracellular cytokine staining, or staining by peptide MHC multimers using FACS analysis. ${ }^{156}$

In $C D$ research, $T$ cells cultured and expanded in the presence of gluten proteins in vitro over several weeks (polyclonal "T cell lines") and then isolated after further in vitro culture as homogeneous (monoclonal) "T cell clones" with a single $\mathrm{T}$ cell receptor have been typical. ${ }^{6-19}$ Whether $\mathrm{T}$ cell lines and clones are informative regarding in vivo $\mathrm{T}$ cell specificity is determined by whether they are derived from $\mathrm{T}$ cells that previously encountered gluten in vivo (memory) rather than naïve $\mathrm{T}$ cells, and whether antigen presentation in vitro reflects in vivo processes. In CD, such experiments are further complicated by gluten being partially digested in the gut $^{20}$ and then deamidated by mucosal tissue transglutaminase (tTG) before recognition by T cells. ${ }^{13}$

That most gliadin specific $\mathrm{T}$ cell clones from peripheral blood of healthy ${ }^{10}$ and $\mathrm{CD}^{9}$ individuals are not HLA DQ2 restricted and not specific for deamidated gliadin, ${ }^{13}$ while nearly all CD intestinal biopsy derived $\mathrm{T}$ cell clones specific for gliadin are HLA-DQ2 or DQ8 restricted $^{78}$ and specific for deamidated gliadin, ${ }^{13}$ has led to the view that studies of peripheral blood $\mathrm{T}$ cells in $\mathrm{CD}$ are not informative. ${ }^{13}$

This assessment may be true for $\mathrm{T}$ cell clones isolated in vitro, but six days after eating gluten polyclonal effector $\mathrm{T}$ cells specific for gluten appear in the peripheral blood of CD subjects normally following a gluten free diet (GFD). ${ }^{21}$ Presumably gluten specific $\mathrm{T}$ cells are present in peripheral blood due to antigen driven expansion in the intestine and subsequent spillover/recirculation via the systemic circulation. Such $\mathrm{T}$ cells are measurable by overnight culture of peripheral blood mononuclear cells (PBMC) and single cell cytokine secretion (IFN- $\gamma$ ELISPOT). This technique identified p57-73 (QLQPFPQPQLPYPQPQS) in A-gliadin as a potent stimulus for IFN- $\gamma$ secretion by HLA DQ2 restricted CD4 $\mathrm{T}$. cells. ${ }^{21}$ Glutamine at position 65 in p57-73 is specifically deamidated by tTG Q $\rightarrow$ E65 (QE65) and causes at least a sixfold increase in peripheral blood $\mathrm{T}$ cell reactivity. The peptide p57-73 QE65 includes two overlapping sequences, DQ2- $\alpha$-I (PFPQPELPY) and DQ2- $\alpha$-II (PQPELPYPQ), that are common epitopes for CD intestinal

Abbreviations: $\mathrm{CD}$, coeliac disease; IFN- $\gamma$, interferon $\gamma$; IL, interleukin; GFD, gluten free diet; PBMC, peripheral blood mononuclear cells; $\mathrm{TTG}$, tissue transglutaminase; EMA, endomysial antibodies; PPD, purified protein derivative of Mycobacterium bovis; SFU, spot forming units 
Table 1 Demographics of the subjects

\begin{tabular}{lclll}
\hline & $\mathbf{n}$ & Age (y) & Sex (F:M) & GFD \\
\hline CD: long term GFD & 59 & $47(19-70)$ & $37: 22$ & 2 y (0.5-29) \\
CD: new diagnosis & 13 & $56(19-65)$ & $9: 4$ & 0 \\
Healthy controls & 9 & $35(31-54)$ & $3: 6$ & 4 wks \\
\hline \multirow{2}{*}{$\begin{array}{l}\text { Values are median (range) or number. } \\
\text { CD, coeliac disease; GFD, gluten free diet. }\end{array}$}
\end{tabular}

gliadin specific T cell clones. ${ }^{14}{ }^{17-18}$ Interestingly, intraduodenal instillation of LQLQPFPQPQLPYPQPQLPY causes villous atrophy and intraepithelial lymphocytosis comparable with gluten in volunteers with CD. ${ }^{22}$

Despite the consistency of findings using peripheral blood effector $\mathrm{T}$ cells after gluten challenge and intestinal biopsy derived clones, there have been no further reports utilising in vivo gluten challenge, and questions remain regarding the interpretation and reproducibility of this technique. If short term gluten challenge does induce effector $\mathrm{T}$ cells in peripheral blood representative of intestinal gluten specific $\mathrm{T}$ cells in $\mathrm{CD}$, the technique would be valuable for many $\mathrm{CD}$ related as well as other broader studies of antigen specific intestinal responses.

The aims of this study were: (1) to establish the quantitative nature of IFN- $\gamma$ ELISPOT for detection of p5773 QE65 and gliadin specific T cells; (2) to determine the phenotype, HLA restriction, and intestinal integrin expression of peripheral blood gliadin specific $\mathrm{T}$ cells evoked by in vivo gluten challenge; (3) to define the clinical requirements (prior antigen exposure) for gluten challenge to predictably induce gluten specific $\mathrm{T}$ cells in blood; and (4) to exploit IFN- $\gamma$ ELISPOT and gluten challenge to determine the consistency and contribution of $\mathrm{T}$ cells specific for p57-73 QE65 to the polyclonal $\mathrm{T}$ cell response to deamidated gliadin in a large number of subjects with $\mathrm{CD}$, as there have been conflicting reports on the consistency of responses to this peptide in CD. ${ }^{14}{ }^{17-18}$

\section{MATERIALS AND METHODS}

\section{Subjects and antigen challenge}

The study was approved by local ethics committees in Oxford and Melbourne. CD was diagnosed according to ESPGAN criteria. ${ }^{23}$ Demographics of subjects are shown in table 1. Long term GFD CD subjects were recruited by invitation to those attending the Coeliac Clinic at the John Radcliffe Hospital $(n=49)$ or through the local newsletter of the Coeliac Society of Victoria $(n=10)$-all believed they were strictly compliant with a GFD and were endomysial (EMA) or tTG IgA negative, and none used immunosuppressants. Patients newly diagnosed with CD (EMA positive) attending the Coeliac Clinic (Oxford) from April to October 2000 who had not commenced a GFD were invited to participate-all except one agreed $(n=13)$. Healthy controls (EMA negative) were recruited from the Gastroenterology Unit and research staff at the John Radcliffe Hospital $(n=9)$ and followed a
GFD for four weeks prior to gluten challenge. Gluten challenge consisted of four slices $(4 \times 50 \mathrm{~g})$ of white bread daily for three days. Exceptions were in four subjects who only ate two slices of bread due to vomiting and abdominal pain which resolved within six hours (there were no other more severe adverse reactions), and three other subjects who ate four slices of bread daily for 10 days. Peripheral venous blood was drawn in all cases on day 6 after commencing the gluten challenge. Blood was also obtained before the three day gluten challenge (day $0, n=12$ ) and on day $7(n=28)$ for comparison with day 6 , and during the 10 day challenge blood was collected on days 0,6 , and 10. Seven subjects agreed to two three day gluten challenges at least three months apart. $H L A-D Q A$ and $H L A-D Q B$ genotypes were determined using peripheral blood DNA and polymerase chain reaction with sequence specific primer mixes. ${ }^{24-26}$ HLADQ genotype data for subjects is shown in table 2 .

\section{Peptides}

Synthetic peptides ( $>70 \%$ purity) were purchased from Research Genetics (Huntsville, Alabama, USA); their sequences are shown in table 3. Initially, A-gliadin p57-73 QE65 was used but subsequently substituted for homologues corresponding to Genbank sequences differing by one amino acid at the C terminal, AG01 E9 and AG02 E9, with bioactivity identical to A-gliadin p57-73 QE65 (manuscript in preparation). Digestion of gliadin (Sigma G-3375) and deamidation with guinea pig liver tTG (Sigma T-5398) is described elsewhere. ${ }^{21}$

\section{IFN- $\gamma$ ELISPOT}

ELISPOT for IFN- $\gamma$ has been described previously. ${ }^{21}$ Mycobacterium tuberculosis purified protein derivative (PPD RT49) (Serum Institute, Copenhagen, Denmark) $(5 \mu \mathrm{g} / \mathrm{ml})$ or tetanus toxoid (Commonwealth Serum Laboratories, Melbourne, Australia) (10 light forming units/ $\mathrm{ml}$ ) was used as a positive control. Spot forming units (SFU) in individual wells were counted using an automated ELISPOT reader (AID ELISPOT Reader System; AID Autoimmun Diagnostika GmbH, Germany). Intra-assay per cent coefficient of variation of SFU $/ 10^{6} \mathrm{PBMC}$ was $18 \%$ based on six duplicate assays of p57-73 QE65 (25 $\mu \mathrm{g} / \mathrm{ml})$ incubated with $0.5 \times 10^{6}$ cells in five CD subjects in Oxford and, in Melbourne, $14 \%$ based on six duplicates in six CD subjects (all with $>20 \mathrm{SFU} /$ well).

Table 2 HLA-DQ genotype of the subjects

\begin{tabular}{llllll}
\hline DQA & DQB & Abbreviation & $\begin{array}{l}\text { Long term } \\
\text { GFD }\end{array}$ & $\begin{array}{l}\text { New } \\
\text { diagnosis }\end{array}$ & $\begin{array}{l}\text { Healthy } \\
\text { controls }\end{array}$ \\
\hline 0501 only & 0201 only & DQ2.5cis+2.5cis & 10 & 3 & \\
0201,0501 & 0201,0202 & DQ2.5cis+2.2 & 16 & 2 & 1 \\
0501,0301 & 0201,0302 & DQ2.5cis+8 & 5 & 1 & 7 \\
0501, other & 0201, other & DQ2.5cis & 23 & 7 & 7 \\
0505,0201 & 0202,0301 & DQ2.5trans & 5 & & \\
\hline
\end{tabular}

GFD, gluten free diet. 
Table 3 Details of peptides

\begin{tabular}{lll}
\hline Abbreviation & Accession No/source & Sequence \\
\hline p57-73 & A-gliadin protein sequence & QLQPFPQPQLPYPQPQS \\
p57-73 QE65 & Deamidation product of $577-73$ Q $\rightarrow$ E65 51 & QLQPFPQPELPYPQPQS \\
AG01 E9 & Triticum aestivum $\alpha / \beta$-gliadins P04722 $(77-93)$ Q $\rightarrow$ E85 & QLQPFPQPELPYPQPQP \\
AG02 E9 & Triticum aestivum $\alpha / \beta$-gliadins P04724 (77-93) Q $\rightarrow$ E85 & QLQPFPQPELPYPQPQL \\
\hline
\end{tabular}

\section{Cell depletion and anti-class II antibody blocking}

PBMC were depleted with precoated anti-CD4 and anti-CD8 magnetic beads (Dynal, Norway), and anti- $\beta 7$ and anti- $\alpha^{\mathrm{E}}$ integrin coated beads prepared according to the manufacturer's instructions using antirat IgG coated beads and antimouse IgG coated beads incubated with rat antihuman $\beta 7$ IgG (clone FIB504; PharMingen) and mouse antihuman $\alpha^{\mathrm{E}}$ integrin IgG (clone 2G5; Beckman Coulter), respectively. As tTG-gliadin, p57-73 QE65, and PPD IFN- $\gamma$ ELISPOT responses were completely abolished by CD4 depletion and unaffected by CD8 depletion in initial experiments, ELISPOT responses of depleted PBMC were expressed as a percentage of CD8 depleted PBMC IFN- $\gamma$ ELISPOT responses to control for "non-specific" aggregation and depletion. MHC class II restriction was determined as previously described using anti-HLA-DR and anti-HLA-DQ antibody. ${ }^{21}$

\section{Statistics}

ELISPOT responses to medium alone were subtracted from responses to antigen. Non-parametric (Wilcoxon paired rank sum or Mann Whitney) tests were used to compare data. A probability level of 0.05 was considered significant. Doseresponse curves and depletion and blocking data were based on subjects whose PBMC stimulated at least 20 SFU/well to the antigen studied.

\section{RESULTS}

\section{IFN- $\gamma$ ELISPOT dose-response to deamidated gliadin} and p57-73 QE65

In CD subjects on a long term GFD, PBMC collected six days after commencing gluten challenge showed reproducible and dose dependent IFN- $\gamma$ ELISPOT responses to p57-73 QE65 $(\mathrm{n}=8)$ (fig $\mathrm{lA}$ ) and tTG deamidated chymotrypsin digested gliadin ("tTG-gliadin") $(\mathrm{n}=5) \quad$ (fig $\mathrm{lB})$. IFN- $\gamma$ ELISPOT responses to p57-73 QE65 were maximal at between 10 and $100 \mu \mathrm{g} / \mathrm{ml}$ (median $20 \mu \mathrm{g} / \mathrm{ml}$ ), and half maximal (EC50) at
$0.5-5 \mu \mathrm{g} / \mathrm{ml}$ (median $2 \mu \mathrm{g} / \mathrm{ml}$ ). Dose-response curves for the two DQ2.5cis+2.2 subjects were similar to five with DQ2.5cis and one with DQ2.5cis+8. Optimal concentrations for tTGgliadin and gliadin were not clearly reached even at $500 \mu \mathrm{g} / \mathrm{ml}$. However, PBMC IFN- $\gamma$ ELISPOT responses to gliadin were equivalent to approximately 10 times lower concentrations of tTG-gliadin.

\section{Peripheral blood CD4+ $\alpha 4 \beta 7+$ HLA-DQ2 restricted gliadin specific $\mathrm{T}$ cells}

The frequency of peripheral blood p57-73 QE65 specific T cells was not sufficient for FACS based analysis and therefore expression of CD4, CD8, and $\alpha^{\mathrm{E}}(\mathrm{CD} 103)$ and $\beta 7$ integrin proteins associated with homing to the intestinal epithelium $\left(\alpha^{\mathrm{E}} \beta 7\right)$ and lamina propria $(\alpha 4 \beta 7)^{28}{ }^{29}$ was determined by depletion of freshly isolated PBMC using immunomagnetic beads. In PBMC from nine subjects, both tTG-gliadin and p57-73 QE65 IFN- $\gamma$ responses were abolished by depletion with anti- $\beta 7$ integrin coated beads, but were generally unaffected by anti- $\alpha^{\mathrm{E}}$ integrin coated beads (fig $2 \mathrm{~A}$ ). IFN- $\gamma$ ELISPOT responses to purified protein derivative of Mycobacterium bovis (PPD) were unaffected by depletion with anti- $\alpha^{\mathrm{E}}$ integrin coated beads and only modestly reduced by depletion with anti- $\beta 7$ integrin coated beads. FACS analysis demonstrated that treatment of PBMC with anti- $\beta 7$ integrin and anti- $\alpha^{\mathrm{E}}$ integrin coated beads depleted CD4+ $\beta 7+$ PBMC by $99 \%$ and CD $4+\alpha^{\mathrm{E}}+$ PBMC by $47 \%$ (data not shown).

Preincubation of PBMC from eight CD subjects (HLA DQ2.5cis, $\mathrm{n}=2 ; \quad \mathrm{DQ} 2.5$ cis +2.5 cis, $\mathrm{n}=3 ; \quad \mathrm{DQ} 2.5$ cis +2.2 cis, $\mathrm{n}=3$ ) on day 6 after commencing gluten challenge with anti-HLA-DQ antibody (SPVL3) reduced IFN- $\gamma$ ELISPOT responses to tTG-gliadin $(100 \mu \mathrm{g} / \mathrm{ml})$ to a median of $5 \%$ compared with no antibody (interquartile range 2-7\%, $\mathrm{p}<0.008$, by one tailed Wilcoxon rank sum test, $\mathrm{n}=8$ ), $\mathrm{p} 57-$ $73 \mathrm{QE} 65(50 \mu \mathrm{g} / \mathrm{ml})$ to a median of $24 \%$ (interquartile range $15-34 \%, \mathrm{p}<0.008, \mathrm{n}=8)$, and PPD $(5 \mu \mathrm{g} / \mathrm{ml})$ to a median of
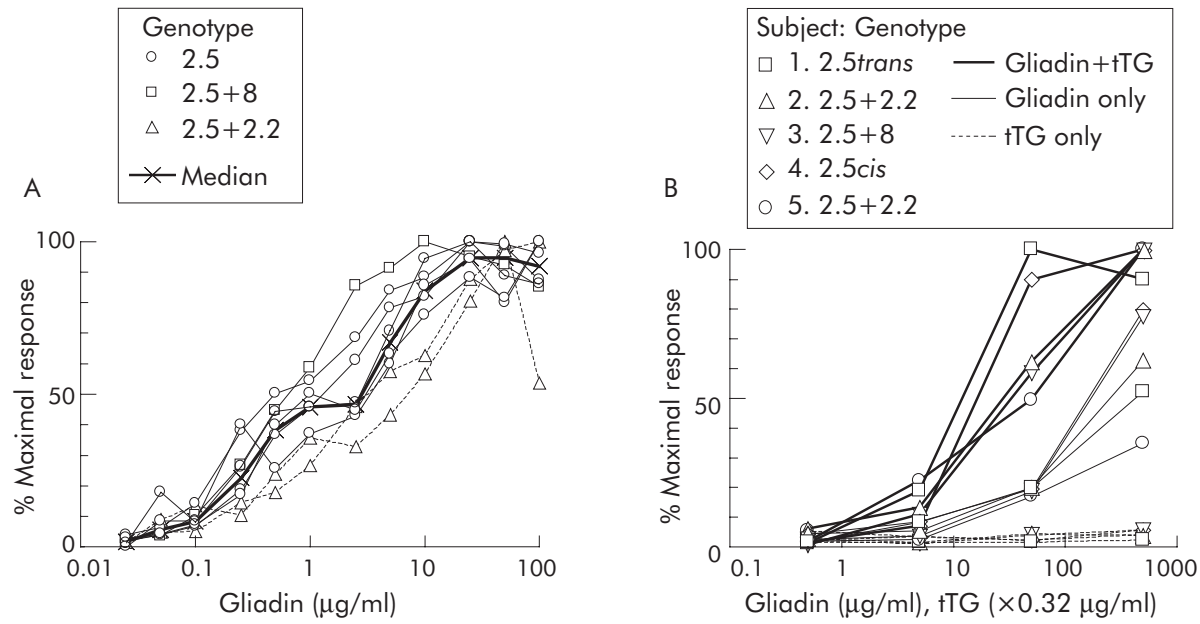

Figure 1 Peripheral blood mononuclear cell (PBMC) interferon $\gamma$ (IFN- $\gamma$ ) ELISPOT dose-response relationship for individual coeliac disease subjects to A-gliadin p57-73 QE65 $(n=8)(A)$ and chymotrypsin digested gliadin with or without deamidation by tissue transglutaminase (tTG), and tTG alone $(n=5)(B)$. Results are expressed as per cent of an individual's maximal response to any concentration of p57-73 QE65 or tTG-gliadin, respectively. 

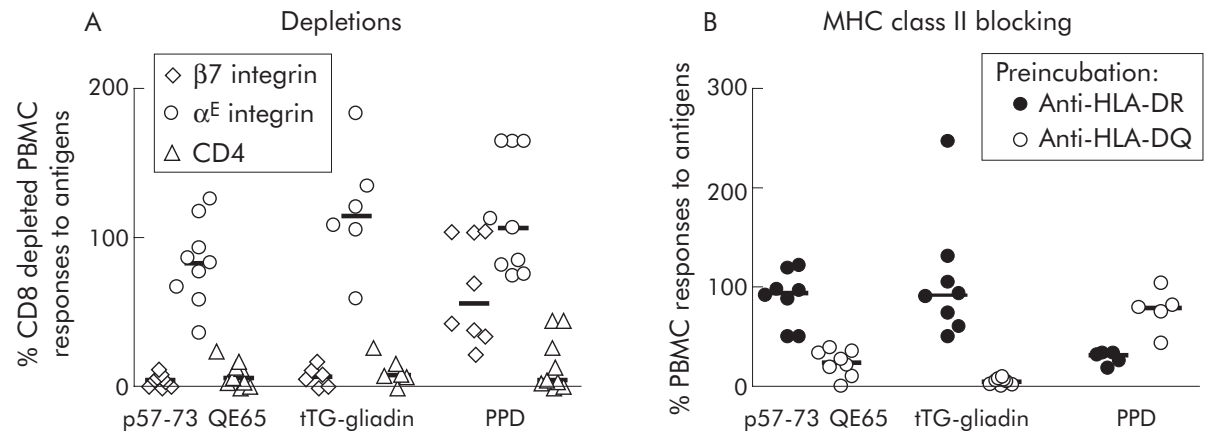

Figure 2 Interferon $\gamma$ (IFN- $\gamma$ ) ELISPOT responses of peripheral blood mononuclear cells (PBMC) to p57-73 QE65 $(25 \mu \mathrm{g} / \mathrm{ml})(\mathrm{n}=9)$, tissue transglutaminase $(\mathrm{tTG})$ deamidated gliadin $(100 \mu \mathrm{g} / \mathrm{ml})(\mathrm{n}=6)$, and purified protein derivative of Mycobacterium bovis (PPD $5 \mu \mathrm{g} / \mathrm{ml})(\mathrm{n}=8)(\mathrm{median}$ marked) after depletion using anti-integrin- $\beta 7$ or $-\alpha^{E}$, or anti-CD4 immunomagnetic beads, in HLA-DQ2+ coeliac disease subjects on a long term gluten free diet, six days after commencing a three day gluten challenge (A). Results are expressed as per cent of CD8 depleted PBMC responses to antigens; not every subject responded to each antigen. IFN- $\gamma$ ELISPOT responses of PBMC to p57-73 QE65 $(50 \mu \mathrm{g} / \mathrm{ml})(\mathrm{n}=8)$, tTG deamidated gliadin $(100 \mu \mathrm{g} / \mathrm{ml})(\mathrm{n}=8)$, and PPD $(5 \mu \mathrm{g} / \mathrm{ml})(\mathrm{n}=5)$ (median marked) following preincubation for one hour with anti-HLA-DR (L243) or anti-HLA-DQ (SPvL3) antibody (B). Results are expressed as per cent of PBMC responses to antigens without preincubation with antibody.

$80 \%$ (range $5-80 \%$, not significant, $\mathrm{n}=5$; three subjects did not respond to PPD) (fig $2 \mathrm{~B}$ ). Preincubation with anti-HLA-DR antibody (L243) did not significantly reduce IFN- $\gamma$ ELISPOT responses to any of the antigens compared with no antibody (tTG-gliadin: median 92\%, interquartile range $67-118 \%, \mathrm{n}=8$; p57-73 QE65: median 94\%, interquartile range 69-109\%, $\mathrm{n}=8$; PPD: median $32 \%$, range $18-34 \%, n=5$ ).

\section{Low frequency p57-73 QE65 T cells in untreated CD disappear with a GFD}

In newly diagnosed CD $(n=13)$, IFN- $\gamma$ ELISPOT responses to both p57-73 QE65 $(25 \mu \mathrm{g} / \mathrm{ml})$ and tTG-gliadin $(100 \mu \mathrm{g} / \mathrm{ml})$ were close to minimum detection limits. The median response to p57-73 QE65 was 13 SFU/10 ${ }^{6}$ PBMC (range 2$18, \mathrm{n}=11$ ) compared with 7 for medium alone (range 4-11; $\mathrm{p}<0.003$ by one tailed Wilcoxon paired rank sum test) (fig 3A); for tTG-gliadin the median response was 26 (range 8-246, $\mathrm{n}=11$ ) compared with 9 for tTG alone (range 3-39, $\mathrm{n}=11 ; \mathrm{p}<0.01$ ) (fig 3B). One, two, and eight weeks after commencing GFD, IFN- $\gamma$ ELISPOT responses to p57-73 QE65 were no different from medium alone. IFN- $\gamma$ ELISPOT responses to tTG-gliadin were maintained at one week (median 34, range $3-181, \mathrm{n}=4$ ) but undetectable at two weeks $(n=5)$ and eight weeks $(n=7)$. IFN- $\gamma$ ELISPOT responses to PPD did not change with a GFD (fig 3C).

\section{Gluten challenge induces peripheral blood T cells after two weeks of a GFD}

Three day gluten challenge was performed one, two, and eight weeks after patients newly diagnosed with CD commenced a GFD. After one week of a GFD, gluten challenge did not induce IFN- $\gamma$ ELISPOT responses to p5773 QE65 or tTG-gliadin (fig 3A, B) but after a GFD for two weeks and even more so after eight weeks, gluten challenge induced highly significant increases in IFN- $\gamma$ ELISPOT responses to p57-73 QE65 (two weeks day 0: median $8 \mathrm{SFU} / 10^{6}$ PBMC (range 0-8); day 6: 22 (5-50); day $0 v$ day $6, \mathrm{p}<0.022$ Wilcoxon paired rank test one tailed, $\mathrm{n}=5$; eight weeks day 0: 3 ( $1-6)$; day 6: $66(8-119) ; \mathrm{p}<0.011, \mathrm{n}=7$ ) and tTG-gliadin (two weeks day 0: 11 (range 4-12); day 6: 28 (6116); $\mathrm{p}<0.022, \mathrm{n}=5$; eight weeks day 0: 4 (2-26); day 6: 68 (7-157); $\mathrm{p}<0.01$ ), but not PPD (fig $3 \mathrm{~A}-\mathrm{C}$ ) or tTG alone (data not shown). Responses to p57-73 QE65 induced by gluten challenge by eight weeks after commencing GFD $(n=7)$ were not significantly different from those in CD subjects on a long term GFD (median $83 \mathrm{SFU} / 10^{6} ; \mathrm{n}=59, \mathrm{p}=0.17$ Mann Whitney test).

\section{Gliadin specific T cells in healthy HLA-DQ2 subjects after gluten challenge}

Gluten challenge weakly induced IFN- $\gamma$ ELISPOT responses to gliadin $(500 \mu \mathrm{g} / \mathrm{ml})$ in healthy HLA-DQ2 subjects after four weeks of a GFD (day 0 median: $3 \mathrm{SFU} / 10^{6} \mathrm{PBMC}$, interquartile range $0-5$; day 6 median: 21 , interquartile range 2-32; $\mathrm{n}=9 \mathrm{p}<0.01$ ) (fig $4 \mathrm{~A}$ ). Deamidation did not enhance IFN- $\gamma$ ELISPOT responses to gliadin in healthy subjects before or on day 6 after gluten challenge (median ratio day 6 SFU tTG-gliadin to no tTG: 0.6) (fig 4B). In one healthy subject, there was induction of IFN- $\gamma$ ELISPOT responses to gliadin $(500 \mu \mathrm{g} / \mathrm{ml})$ (day $020 \mathrm{SFU} / 10^{6} \mathrm{PBMC}$, day 6 171)
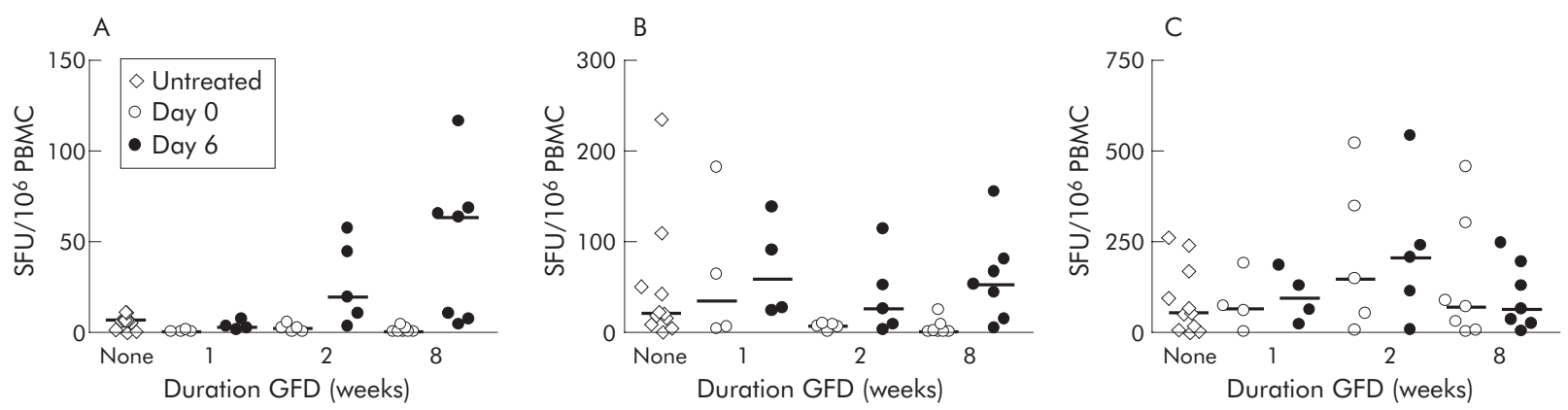

Figure 3 Interferon $\gamma$ (IFN- $\gamma$ ) ELISPOT responses (spot forming units (SFU)/10 6 peripheral blood mononuclear cells (PBMC), median marked) to $\mathrm{p} 57-$ 73 QE65 $(25 \mu \mathrm{g} / \mathrm{ml})(\mathrm{A})$, tissue transglutaminase (tTG) deamidated gliadin $(100 \mu \mathrm{g} / \mathrm{ml})(\mathrm{B})$, and purified protein derivative of Mycobacterium bovis (PPD $5 \mu \mathrm{g} / \mathrm{ml}$ ) (C) in patients with a new diagnosis of coeliac disease before adopting a gluten free diet (GFD) ("None $\left.{ }^{\prime \prime}\right)(\mathrm{n}=11)$, and immediately before (Day 0) and on day 6 after a three day gluten challenge performed after following a strict GFD for one $(n=4)$, two $(n=5)$, or eight $(n=7)$ weeks. 

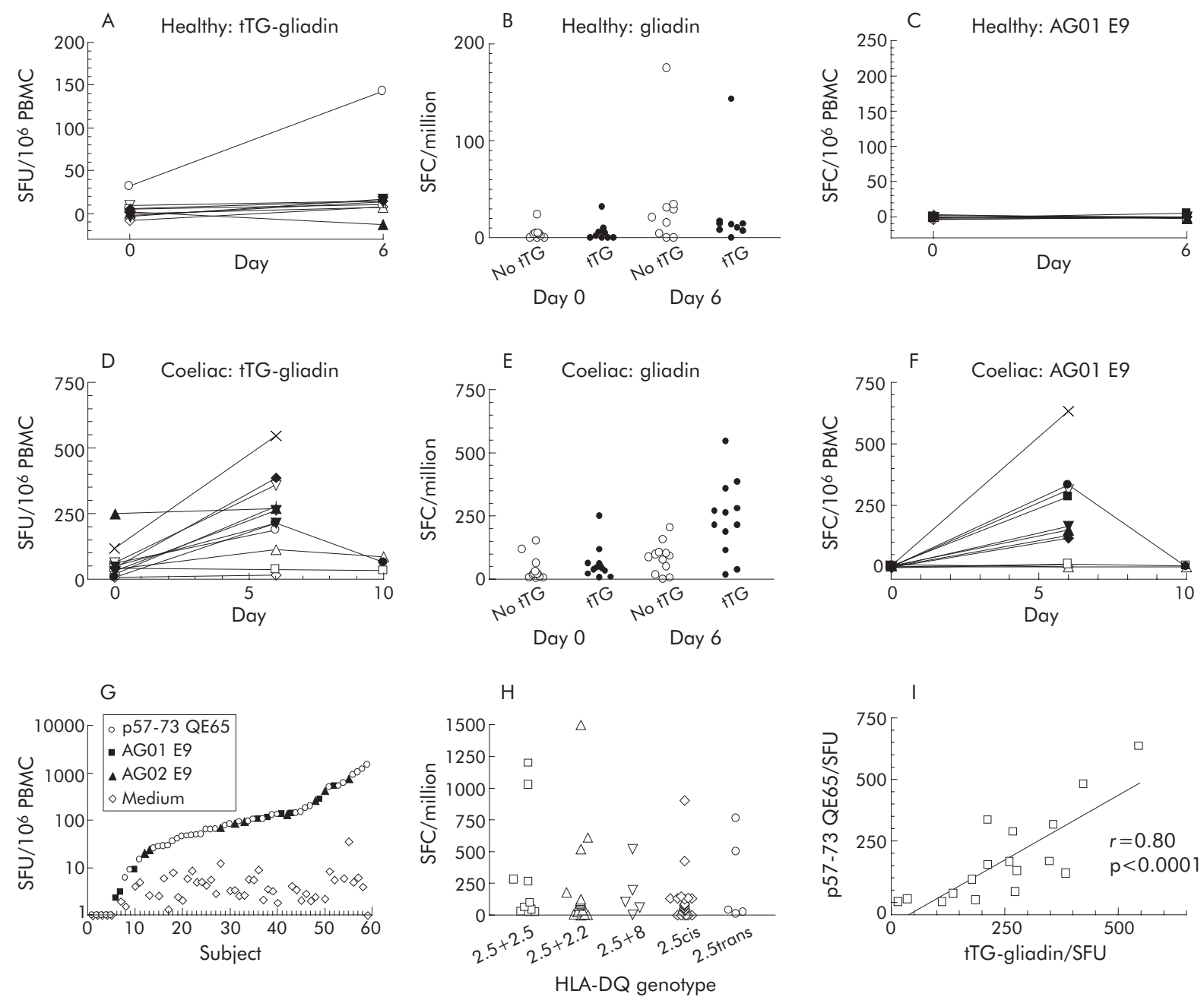

Figure 4 Interferon $\gamma$ (IFN- $\gamma$ ) ELISPOT responses of peripheral blood mononuclear cells (PBMC) from individual HLA-DQ2+ healthy subjects after a gluten free diet (GFD) for four weeks $(n=9)(A)$ and coeliac disease (CD) subjects on a long term GFD $(n=12)(D)$ to tissue transglutaminase (tTG) deamidated gliadin $(500 \mu \mathrm{g} / \mathrm{ml})$ before and on day 6 and day 10 after commencing a three day gluten challenge. IFN- $\gamma$ ELISPOT responses of the same healthy (B) and CD (E) subjects to gliadin $(500 \mu \mathrm{g} / \mathrm{ml}$ ) with or without $\mathrm{TTG}$ deamidation (mean (SEM)). Individual IFN- $\gamma$ ELISPOT responses to the p57-73 QE65 homologue, AG01 E9 (20 $\mu \mathrm{g} / \mathrm{ml}$ ) (see table 1 for sequence), in healthy (C) and CD (F) subjects. Individual IFN- $\gamma$ ELISPOT responses of all HLA-DQ2+ CD subjects on a long term GFD $(\mathrm{n}=59)$ to medium alone or $\mathrm{p57}-73$ QE65 (25 or $50 \mu \mathrm{g} / \mathrm{ml})$, AG01 E9 (20 $\mu \mathrm{g} / \mathrm{ml})$, or AG02 E9 $(100 \mu \mathrm{g} / \mathrm{ml}$ ) (see table 3 for sequences) (G), and according to HLA-DQ genotype (H). IFN- $\gamma$ ELISPOT responses to tTG deamidated gliadin (500 $\mu \mathrm{g} /$ $\mathrm{ml}$ ) on day 6 after a three day gluten challenge correlated with p57-73 QE65 in 17 individual CD subjects (I). SFU, spot forming units.

similar to those seen in CD subjects except that deamidation did not increase the response to gliadin (no tTG: 175 SFU/ $10^{6} ;+$ tTG: 171). Gluten challenge did not induce responses to the A-gliadin 57-73 QE65 homologue, AG01 E9 $(20 \mu \mathrm{g} / \mathrm{ml})$, in any healthy subject (fig 4C).

\section{Consistency and magnitude of the p57-73 QE65 T cell response in coeliac disease}

In agreement with our earlier study, ${ }^{21} 11 / 12$ CD subjects showed induction of tTG-gliadin specific IFN- $\gamma$ ELISPOT responses following gluten challenge (tTG-gliadin day 0: median 43, range 7-250; day 6: median 238, range 17-546, $\mathrm{p}<0.02$; gliadin $500 \mu \mathrm{g} / \mathrm{ml}$ day 0 : median 20, range 2-150 SFU $/ 10^{6}$ PBMC; day 6 median 81, range 1-203, NS) (fig $4 \mathrm{D}, \mathrm{E}$ ) that was matched by potent induction of responses to AG0l E9 $(20 \mu \mathrm{g} / \mathrm{ml}$ day 0: median 0, range $0-8$; day 6: median 139, range $0-663, \mathrm{n}=12, \mathrm{p}<0.003$ ) (see fig $4 \mathrm{~F}$ ).

Median IFN- $\gamma$ ELISPOT response of PBMC collected from 59 CD subjects on a long term GFD to "optimal" concentrations $(20-100 \mu \mathrm{g} / \mathrm{ml}$ ) of p57-73 QE65 (or AG01 E9 or AG02 E9) on day 6 after gluten challenge was 83 SFU $/ 10^{6}$ (range
1-1500, interquartile range 27-151) (fig 4G). In 50/59 (85\%) subjects, IFN- $\gamma$ ELISPOT PBMC responses to p57-73 QE65 were between 10 and $1500 \mathrm{SFU} / 10^{6}$, and to medium alone less than $10 \mathrm{SFU} / 10^{6}$ in 57/59. After a three day gluten challenge in $26 \mathrm{CD}$ subjects, ELISPOT was performed on day 7 as well as on day 6; responses to p57-73 QE65 were maintained but were usually lower on day 7 than on day 6 (day 6: median 91, interquartile range 59-180; day 7: median 69 , interquartile range $37-151 ; p<0.012$ by Wilcoxon paired rank sum two tail test). In six of seven subjects who underwent gluten challenge on two occasions between three and 12 months apart, responses to p57-73 QE65 were present on both occasions (first challenge day 6: median $108 \mathrm{SFU} /$ $10^{6}$, range 46-1500; second challenge day 6: median 39, range 0-170). In three subjects, consumption of bread for 10 days was not associated with greater responses to tTGgliadin or AG01 E9 on day 6 and had fallen by day 10 (fig 4F).

HLA-DQ2 gene dosage was not associated with significant differences in the frequency of p57-73 QE65-specific SFU/10 ${ }^{6}$ PBMC using Mann Whitney one tail non-parametric testing: DQ2.5cis+2.5cis: median 79, interquartile range 27-652, $\mathrm{n}=10 ;$ DQ2.5cis+2.2cis: median 93, interquartile range 
19-154, $\mathrm{n}=16$; DQ2.5cis+8: median 105, range 3-522, $\mathrm{n}=5$; DQ2.5cis: median 70, interquartile range $0-135, \mathrm{n}=23$; DQ2.5trans: median 38, range 9-762, $\mathrm{n}=5$ ) (fig $4 \mathrm{H}$ ).

\section{Correlation between tTG-gliadin and p57-73 QE65 IFN- $\gamma$ ELISPOT responses}

In $C D$ subjects $(n=17)$, day 6 post-gluten challenge IFN- $\gamma$ ELISPOT responses to tTG-gliadin $(500 \mu \mathrm{g} / \mathrm{ml})$ and p57-73 QE65 $(25 \mu \mathrm{g} / \mathrm{ml}, \mathrm{n}=5)$ or AG01 E9 $(20 \mu \mathrm{g} / \mathrm{ml}, \mathrm{n}=12)$ were significantly correlated $(r=0.80, \mathrm{p}<0.0001)$ (see fig $4 \mathrm{I})$. Median IFN- $\gamma$ ELISPOT responses to p57-73 QE65 (25 $\mu \mathrm{g} /$ $\mathrm{ml}$ ) or AG01 E9 $(20 \mu \mathrm{g} / \mathrm{ml}$ ) were $51 \%$ (range $0-155 \%$ ) of those to tTG-gliadin $(500 \mu \mathrm{g} / \mathrm{ml})$, although in $3 / 17 \mathrm{CD}$ subjects responses to p57-73 QE65 were less than 5\% $\left(<9 \mathrm{SFU} / 10^{6} \mathrm{PBMC}\right)$ of those to tTG-gliadin (fig $\left.4 \mathrm{I}\right)$.

\section{DISCUSSION}

In model murine systems, there is persuasive evidence that gastrointestinal and systemic $\mathrm{T}$ cell responses are intimately linked. Oral administration of antigen is followed by proliferation of antigen specific $\mathrm{T}$ cells in gut associated and systemic lymphoid tissue. ${ }^{30}$ Identical $\mathrm{T}$ cell clones are found within the gut lamina propria and thoracic duct, ${ }^{31}$ implying their presence in venous blood and trafficking to tissues where their cognate antigen is presented. Autoantigen (myelin basic protein) specific $\mathrm{T}$ cells transferred to a syngeneic recipient disappear from blood after three days and are exclusively found in tissue expressing myelin basic protein (central nervous system). ${ }^{32}$ Such data would be consistent with gluten challenge stimulating gluten specific memory $\mathrm{T}$ cell proliferation in gut associated lymphoid tissue followed by passage of effector T cells via the thoracic duct to peripheral blood. Presumably, gluten specific T cells circulate in blood until they migrate to tissues (small intestine) expressing an appropriate addressin where they are activated by encounter with their cognate antigen (gluten).

In this study, the phenotype of peripheral blood gluten specific $\mathrm{T}$ cells induced by in vivo gluten challenge was determined by immunomagnetic bead depletion of PBMC as the frequency of relevant T cells was insufficient for FACS based methods. Depletion of PBMC with magnetic beads coated with anti-CD4 or anti- $\beta 7$ integrin, but not anti-CD8 or anti- $\alpha$ E integrin, consistently abolished IFN- $\gamma$ ELISPOT responses to deamidated gliadin and p57-73 QE65. Furthermore, anti-HLA-DQ but not anti-HLA-DR blocked IFN- $\gamma$ ELISPOT responses to deamidated gliadin and p57-73 QE65 in HLA-DQ2.5cis homozygotes and heterozygotes. Therefore, IFN- $\gamma$ ELISPOT detects CD4 T cells in peripheral blood specific for deamidated gliadin and p57-73 QE65 that are likely to be almost exclusively HLA-DQ2 restricted, are induced by in vivo gluten exposure, and are very likely to express the $\alpha 4 \beta 7$ integrin that ligates MAdCAM- 1 and is associated with homing to the intestinal lamina propria. ${ }^{28} 29$

These findings appear to be in conflict with those of Molberg et al that gliadin specific $\mathrm{T}$ cell clones originally derived from peripheral blood or duodenal biopsy material cultured with gliadin are qualitatively different. ${ }^{13}$ However, there are several differences between patients with CD eating gluten to evoke effector $\mathrm{T}$ cells in their blood that are assayed by overnight culture, and in vitro culture of peripheral blood or biopsies with predigested gliadin followed by several additional weeks of culture to generate polyclonal or monoclonal $\mathrm{T}$ cells. Molberg et al report that $\mathrm{T}$ cell clones isolated from CD duodenal tissue are specific for gliadin epitopes generated by endogenous tTG mediated deamidation occurring while biopsies are in short term culture being pulsed with gliadin. ${ }^{15}$ Transglutaminase activity in culture medium alone while pulsing peripheral blood $\mathrm{T}$ cells sufficient to deamidate gliadin to the same degree as intestinal biopsies seems unlikely. It is also unclear whether peripheral blood (and intestinal) clones specific for gliadin are derived from naïve or memory $\mathrm{T}$ cells.

In addition, the frequency of IFN- $\gamma$ secreting p57-73 QE65 specific T cells is very low $(<1 / 100000)$ in peripheral blood except for a window of several days after gluten exposure in individuals normally following a strict GFD. Three day gluten challenge increases the frequency of p57-73 QE65 specific T cells in peripheral blood by up to eight times levels in untreated CD when a GFD is followed for two weeks, and up to 200 times after a GFD is followed for eight weeks or longer. Conversely, gluten challenge is not effective in inducing peripheral blood $\mathrm{T}$ cells specific for deamidated gliadin and p57-73 QE65 if a strict GFD has not been followed for at least two weeks. Induction of gliadin specific T cells by gluten challenge is similar after a GFD for eight weeks in newly diagnosed CD as it is after a long term GFD. We specifically excluded CD subjects on a "long term GFD" if they showed positive EMA or tTG-IgA as markers of suboptimal compliance with GFD.

IFN- $\gamma$ ELISPOT detected $\geqslant 10 \mathrm{SFU} / 10^{6}$ PBMC specific for p57-73 QE65 or one of two near identical homologues in 85\% of 59 HLA-DQ2+ CD subjects on a long term GFD drawn from two countries. The frequency of T cells detected by IFN- $\gamma$ ELISPOT specific for p57-73 QE65 was typically half that for deamidated gliadin $(500 \mu \mathrm{g} / \mathrm{ml})$, indicating that p57-73 QE65 is generally but not always the "dominant" epitope in CD after wheat ingestion. HLA-DQ2 gene dose was not associated with the frequency of p57-73 QE65-specific T cells in peripheral blood after gluten challenge.

In conclusion, in vivo gluten challenge in $\mathrm{CD}$ induces peripheral blood gluten specific HLA-DQ2 restricted CD4 T cells expressing an intestinal lamina propria homing integrin. A-gliadin p57-73 QE65 includes the dominant T cell epitopes for HLA-DQ2 associated CD. Gluten challenge provides a unique opportunity to use peripheral blood for rapid mapping, and quantitative assessment of relevant gluten epitopes, assess other grains toxic in $\mathrm{CD}$, and monitor $\mathrm{T}$ cell responses during the development of therapeutics.

\section{ACKNOWLEDGEMENTS}

Supported by grants from Oxford University Challenge Seed Fund, Graham Bird Memorial Fund, Ramaciotti Foundation, and Cancer Council of Victoria. RPA is the DW Keir Fellow in Clinical Research and Lions Cancer Council Fellow, DvH is a Wellcome Clinician Scientist Fellow, JT-D holds a National Health and Medical Research Council Postgraduate Medical Scholarship, and AVSH is a Wellcome Trust Principal Research Fellow. The cooperation of the Coeliac Society of Victoria and assistance of volunteers for these studies is gratefully acknowledged. RPA is a consultant to BTG International Plc.

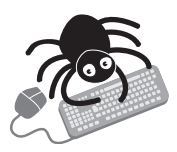

Conflict of interest: declared (the declaration can be viewed on the Gut website at http://www.gutinl.com/ supplemental).

\section{Authors' affiliations}

R P Anderson, J A Tye-Din, Autoimmunity and Transplantation Division, Walter and Eliza Hall Institute, and Department of Gastroenterology, the Royal Melbourne Hospital, Parkville, Victoria, Australia

D A van Heel, Department of Gastroenterology, Hammersmith Hospital, Imperial College, London, UK

M Barnardo, Transplantation Immunology, Nuffield Department of Surgery, Churchill Hospital, University of Oxford, Oxford, UK M Salio, Weatherall Institute of Molecular Medicine, Nuffield Department of Medicine, John Raddliffe Hospital, University of Oxford, Oxford, UK

D P Jewell, Department of Gastroenterology, Nuffield Department of Medicine, Gibson Building, Radcliffe Infirmary, University of Oxford, Oxford, UK 
A V S Hill, Wellcome Trust Centre for Human Genetics, Nuffield Department of Medicine, Churchill Hospital, University of Oxford, Oxford, UK

\section{REFERENCES}

1 Heeger PS, Greenspan NS, Kuhlenschmidt S, et al. Pretransplant frequency of donor-specific, IFN-gamma-producing lymphocytes is a manifestation of immunologic memory and correlates with the risk of posttransplant rejection episodes. J Immunol 1999; 163:2267-75.

2 Matesic D, Valujskikh A, Pearlman E, et al. Type 2 immune deviation has differential effects on alloreactive CD4+ and CD8+ T cells. J Immunol 1998; 161:5236-44

3 Bird JJ, Brown DR, Mullen AC, et al. Helper T cell differentiation is controlled by the cell cycle. Immunity 1998;9:229-37.

4 Nilsen EM, Jahnsen JL, Lundin KEA, et al. Gluten induces an intestinal cytokine response strongly dominated by interferon gamma in patients with coeliac disease. Gastroenterology 1998;115:551-63.

5 Draenert R, Altfeld $M$, Brander $C$, et al. Comparison of overlapping peptide sets for detection of antiviral CD8 and CD4 T cell responses. J Immunol Methods 2003;275:19-29.

6 Quarsten H, McAdam SN, Jensen T, et al. Staining of celiac disease-relevant T cells by peptide-DQ2 multimers. J Immunol 2001;167:4861-8.

7 Lundin KE, Scott H, Hansen T, et al. Gliadin-specific, HLADQ(alpha ${ }^{*} 0501$, beta $1^{*} 0201$ ) restricted T-cells isolated from the small intestinal mucosa of coeliac disease patients. J Exp Med 1993; 178: 187-96.

8 Lundin $\mathrm{KE}$, Scott $\mathrm{H}$, Fausa $\mathrm{O}$, et al. T-cells from the small intestinal mucosa of a DR4, DQ7/DR4, DQ8 coeliac disease patient preferentially recognize gliadin when presented by DQ8. Hum Immunol 1994;41:285-91.

9 Gjertsen HA, Sollid LM, Ek J, et al. T cells from the peripheral blood of coeliac disease patients recognize gluten antigens when presented by HLA-DR, -DQ, or -DP molecules. Scand J Immunol 1994:39:567-74.

10 Jensen K, Sollid LM, Scott H, et al. Gliadin-specific T cell responses in peripheral blood of healthy individuals involve T cells restricted by the coeliac disease associated DQ2 heterodimer. Scand J Immunol 1995;42:166-70.

11 Nilsen EM, Gjertsen HA, Jensen K, et al. Gluten activation of peripheral blood $\mathrm{T}$ cells induces a Th0-like cytokine pattern in both coeliac patients and controls. Clin Exp Immunol 1996;103:295-303.

12 Molberg O, Lundin KE, Nilsen EM, et al. HLA restriction patterns of gliadinand astrovirus-specific CD4+T cells isolated in parallel from the small intestine of coeliac disease patients. Tissue Antigens 1998;52:407-15.

13 Molberg O, McAdam SN, Korner R, et al. Tissue transglutaminase selectively modifies gliadin peptides that are recognized by gut-derived $T$ cells in celiac disease. Nat Med 1998;4:713-17.

14 Arentz-Hansen H, Korner R, Molberg O, et al. The intestinal T-cell response to alpha-gliadin in adult coeliac disease is focussed on a single deamidated glutamine targeted by tissue transglutaminase. J Exp Med 2000;191:603-12.

15 Molberg O, McAdam S, Lundin KE, et al. T cells from coeliac disease lesions recognize gliadin epitopes deamidated in situ by endogenous tissue transglutaminase. Eur J Immunol 2001;31:1317-23.
16 Vader W, Kooy Y, van Veelan $\mathrm{P}$, et al. The gluten response in children with coeliac disease is directed towards multiple gliadin and glutenin peptides. Gastroenterology 2002;122:1729-37.

17 Vader LW, de Ru A, van der Wal Y, et al. Specificity of tissue transglutaminase explains cereal toxicity in celiac disease. J Exp Med 2002; 195:643-9.

18 Arentz-Hansen H, McAdam SN, Molberg O, et al. Celiac lesion T-cells recognize determinants that cluster in regions of gliadins rich in proline residues. Gastroenterology 2002;123:803-9.

19 Vader W, Stepniak D, Kooy Y, et al. The HLA-DQ2 gene dose effect in celiac disease is directly related to the magnitude and breadth of gluten-specific $T$ cell responses. Proc Natl Acad Sci U S A 2003;100:12390-5.

20 Shan L, Molberg O, Parrot I, et al. Structural basis for gluten intolerance in celiac sprue. Science 2002;297:2275-8.

21 Anderson RP, Degano P, Godkin AJ, et al. In vivo antigen challenge in coeliac disease identifies a single transglutaminase-modified peptide as the dominant A-gliadin T-cell epitope. Nat Med 2000;6:337-42.

22 Fraser JS, Engel W, Ellis HJ, et al. Coeliac disease: in vivo toxicity of the putative immunodominant epitope. Gut 2003;52:1698-702.

23 Report of Working Group of European Society of Paediatric Gastroenterology and Nutrition. Revised criteria for diagnosis of coeliac disease. Arch Dis Child 1990;65:909-11.

24 Bunce M, O'Neill CM, Barnardo MC, et al. Phototyping: comprehensive DNA typing for HLA-A, B, C, DRB1, DRB3, DRB4, DRB5 \& DQB1 by PCR with 144 primer mixes utilizing sequence-specific primers (PCR-SSP). Tissue Antigens 1995;46:355-67.

25 Olerup O, Aldener A, Fogdell A. HLA-DQB1 and DQA1 typing by PCR amplification with sequence-specific primers in 2 hours. Tissue Antigens 1993;41:119-34.

26 Mullighan CG, Bunce M, Welsh KI. High-resolution HLA-DQB1 typing using the polymerase chain reaction and sequence-specific primers. Tissue Antigens 1997;50:688-92

27 Kasarda DD, Okita TW, Bernardin JE, et al. Nucleic acid (cDNA) and amino acid sequence of $\alpha$-type gliadins from wheat (Triticum aestivum). Proc Natl Acad Sci U S A 1984:81:4712-16.

28 Cepek KL, Shaw SK, Parker CM, et al. Adhesion between epithelial cells and T lymphocytes mediated by E-cadherin and the alpha E beta 7 integrin. Nature 1994;372:190-3.

29 Berlin C, Berg EL, Briskin MJ, et al. Alpha 4 beta 7 integrin mediates lymphocyte binding to the mucosal vascular addressin MAdCAM-1. Cell 1993;74:185-5.

30 Gutgeman I, Fahrer AM, Altman JD, et al. Induction of rapid T cell activation and tolerance by systemic presentation of an orally administered antigen. Immunity 1998:8:667-73.

31 Arstila T, Arstila TP, Calbo S, et al. Identical T cell clones are located within the mouse gut epithelium and lamina propria and circulate in the thoracic duct. J Exp Med 2000;191:823-34.

32 Flugel A, Berkowicz T, Ritter T, et al. Migratory activity and functional changes of green fluorescent effector cells before and during experimental autoimmune encephalitis. Immunity $2001 ; 14: 547-60$.

\section{Hopkins Endoscopy Prize 2006}

Applications are invited by the Endoscopy Committee of the British Society of Gastroenterology who will recommend to Council the recipient of the 2006 Award. Applications (10 copies) should include:

- A manuscript (two A4 pages only) describing work conducted

- A bibliography of relevant personal publications

- An outline of the proposed content of the lecture, including title

- A written statement confirming that all or a substantial part of the work has been personally conducted in the UK or Eire.

An applicant need not be a member of the Society. The recipient will be required to deliver a 20 minute lecture at the annual meeting of the Society in Birmingham in March 2006. Applications (10 copies) should be made to the Endoscopy Section Secretary, British Society of Gastroenterology, 3 St Andrews Place, London NW1 4LB by 1 December 2005. 